\title{
ViolenCe AGAinst WOMEN. CURRENT PROCEDURAL NEEDS, WITH SPECIAL REFERENCE TO PANAMÁ
}

\begin{abstract}
The violence exerted against women, fruit of the structural inequality to which they have been subjected for centuries, has gone from being invisible and socially acceptable, to being a front-line problem for most of the countries of the world.

Procedural systems have been adapted mostly due to this new social concern, and have included the recommendations of international human rights organizations to their respective legislations.

This article intends to approach the phenomenon of gender violence and a general view of the response that the Administration of Justice must offer battered women, from their perspective as victims in a judicial process. All this, without losing sight of the fact that all procedural systems are susceptible to improvement and that the road to its elimination and the definitive equality between women and men, will be long and complicated, but like any social change, achievable.
\end{abstract}

KEYWORDS: gender violence, domestic violence, women, femicide, feminicide, procedural rights, process.

\section{INTRODUCTION}

As it is indicated by the World Health Organization, the physical or sexual violence is a public health problem that affects more than a third of women in the world, and $35 \%$ of them will suffer violence, coming that from the spouse or sentimental partner the most common, since it covers $30 \%$ of cases.

The Convention on the Elimination of All Types of Discrimination against Women of 1979, intended to prevent this discrimination in both 
the public and private spheres. Subsequently, the General Assembly of the United Nations in its resolution 40/36 on domestic violence in 1985, invited the States to take concrete and urgent measures to prevent it, and provide the necessary assistance to the victims. The same General Assembly, in its Declaration on the elimination of violence against women of 1993, defined this violence as any act of public or private violence because of gender that produces, or is likely to produce, physical, sexual or psychological damage, as well as suffering, threats, coercion or arbitrary deprivation of freedom for women.

Violence against women has emerged as an autonomous violation of human rights, "including any public or private act of gender-based violence that results in, or is likely to result in, physical, sexual or psychological harm or suffering to women, including threats of such acts, coercion or arbitrary deprivation of liberty". It therefore has a broader concept than gender violence.

Nowadays, the phenomenon of gender violence has been defined by the different sectors of the doctrine with the following characteristics:

- violence exerted by men against women, in which the gender of the aggressor and victim is intimately linked to the explanation of said violence,

- social trait, as it has traits of a cultural form to define the identities and relationships between men and women,

- fact derived from the inequality of power between men and women, stemming from the idea of masculine superiority and the patriarchal code,

- instrument, because it is the way to strengthen the male dominance - it is not an end in itself,

- structural and institutional phenomenon, since the norms have historically accepted and legitimized it,

- mentality, because it is based on the lack of strong reaction from women due to the social, psychological and economic dependencies they have with respect to the aggressor,

- general, since it affects all women and is not natural but learned,

- it is tolerated socially, and in certain areas it is not rejected,

- it goes unnoticed. ${ }^{2}$ 
According to the aforementioned definitions, the gender violence is a general fact, since it does not distinguish between social strata, races or religions. The efforts to eradicate this terrible phenomenon by the different States have focused mostly on the urban environment, in which the majority of resources have been installed. However, the United Nations Organization itself has expressed its concern regarding the situation of women living in rural areas and indigenous women ${ }^{3}$, and recommends to the States that their legislation should establish that support services and comprehensive assistance to the victims which will provide the equal access both in the rural zone and in the urban zone ${ }^{4}$.

Another concern highlighted by the report of the UN Special Rapporteur on violence against women, its causes and consequences, prepared in $2011^{5}$ is the low rate of prosecution of perpetrators of crimes against women, which, in her opinion, reinforces the victims' belief that the judicial system does not respond to violence and perpetrators can go unpunished. In the specific case of Panama, the "Diagnosis on the application of the criminal normative framework regarding the elimination of violence against women in judicial resolutions"6, validated in 2011, shows a significant gap between the issues of violence against women that are reported and those that are prosecuted, as nearly half of these cases end with dismissal.

Panama has been aware of this problem for years and it is leading among the surrounding countries, in legislative, social and training measures to reduce the number of cases of violence against women, by the mere fact of being women.

Finally, it should be noted that the purpose of the article is limited to the strict procedural issues related to violence against women, and other issues of crucial importance, such as the empowerment of victims, protective measures, or social aid are left unaddressed requiring a more extensive study than the present one.

\section{Procedural guidelines}

Once the battered woman is immersed in a judicial proceeding, either on her own initiative, by a third party, or by the authorities, she faces a process that is usually slow, tedious, painful and subject to a series of formalities 
and legal terms that she does not understand. These processes, according to the international norms that will be indicated, must have the following characteristics in order to guarantee a swift and effective response for women, and not subject them to victimization twice:

\section{SimplificAtion OF PROCEDURES}

A fact of gender violence can have consequences in different strata apart from strictly criminal aspect. The initial procedure should cover the maximum number of possible pronouncements, and in any case, with swift procedures and free legal assistance for women in order to be placed on equal terms with the man being investigated, who has a pro bono lawyer in case that he does not want, or cannot afford a lawyer of his own choice.

a) Thus, damages ${ }^{7}$ should be judged in the same procedure in which criminal liability is decided. The opposite supposes prolonging the suffering of the victim who does not receive reparations for the moral damage she has suffered ${ }^{8}$ and it is submitted to the commonly referred to as secondary victimization, that is to say, the submission of those who have already been victims of a crime, to the bureaucracy and slow administrative procedures, with the new economic outlay that it entails, and the emotional impact. In addition, the truth is that a statement about the damage caused, after several years, is of little moral reparation.

This principle of avoiding revictimization is integrated into the Law of Panama through Agreement No. 626 of October 15, 2009, of the Plenary of the Supreme Court of Justice ${ }^{9}$, which approves the institutional policy of access to justice and gender of the judicial body, which is established in its article 1:

The institutional policy of access to justice is based on the following principles:

[...]

\section{No revictimization.}

The obligations of the officials of the judicial power, not to carry out acts or omissions that cause damage or affect to those who come to seek justice and claim their right. 
The same Agreement, provides in its guidelines:

8. Promote the friendly participation of the victim of gender violence in the process, avoiding her revictimization, informing her about the process and her rights, providing judicial advice and accompaniment to face the process.

The agreement $n^{\circ} 244$ of the Supreme Court of Panama, of April 13, $2011^{10}$ that adopts the bill of rights of the people before the justice system in the judicial organ of the Republic of Panama, recognizes in article 20, the right to the least expensive appearance possible:

All people have the right to make their personal appearance as inexpensive as possible.

To this end, his or her personal appearance may only be demanded when it is essential, in accordance with the applicable law, and the concentration in a single day of all the actions that must be practiced with the person concerned shall be sought.

[...]

Lastly, The 100 Brasilia Rules on Access to Justice for People in Vulnerability ${ }^{11}$, defines victimization and in its rule 12 states:

12. The adoption of the appropriate measures to mitigate the negative effects of the crime (primary victimization) will be encouraged. They will also ensure that the damage suffered by the victim of the crime is not augmented as a result of their contact with the justice system (secondary victimization).

[...]

\section{Rule 41 states:}

The importance of multidisciplinary teams, made up of professionals from different areas, to improve the response of the judicial system to the demand for justice of a person in a vulnerable condition, is of key importance.

Finally, rule 69 states:

It is advisable to avoid unnecessary appearances, in such a way that they only have to appear when it is strictly necessary according to the legal regulations. The concentration on the same day of the practice of the various actions in which the same person must participate will also be sought.

Panamanian legislation allows this possibility to jointly process the criminal and civil liability derived from the crime through an incident, as provided in articles 1972 and 1973 of the Judicial Code ${ }^{12}$ : 


\section{Article 1972:}

Once the condemnatory sentence has been executed and the civil liability established, its execution will be promoted before the judge who declared civil responsibility. In crimes against patrimony, it will include the obligation of restoring the object of the crime, with payment of any deterioration that has suffered, if it were possible. If it is not, its equivalent will be paid, after a judicial estimate. The amount of compensation will be set by the courts, through the means established by this Code and in accordance with the provisions of Title VI of Book I of the Criminal Code.

\section{Article 1973:}

The claim for compensation for the material and moral damage caused to the victim, his or her family or a third party, must be presented by means of an incident during the plenary, that is, once the judgment order has been enforced.

In the incidental claim, the amount of the material damage will be recorded and the corresponding evidence will be provided.

Another advantage of coming to a resolution regarding criminal and civil liability in the same sentence is the fact that the same judge who presides over both issues, guarantees a better knowledge of the facts, avoids possible malfunctions and even contradictory judgments, and ultimately, gives a better response to the victim.

In my visit to that country in 2017, to participate in Technical Assistance to make a diagnosis on the application of the criminal legal framework in matters of gender in judicial decisions, I was able to conclude that the use of this procedure is minimal, because in the cases analyzed, only criminal and civil responsibility had been processed jointly in $1.35 \%$ of the cases.

Reparation of the damage caused by this type of crime requires concrete measures of compensation, in order to satisfy the specific needs of each woman, guiding the reparations to subvert, instead of reforming, the patterns of structural subordination, hierarchies based on gender, etc. which are the causes of the violence suffered by women. This individualization of the compensation was implemented by the Inter-American Court of Human Rights in its ruling on the case of Esmeralda Herrera Monreal, 
Laura Berenice Ramos Monárrez and Claudia Ivette González (cotton field) against Mexico, on November 16, 2009, in which the Inter-American Court, for the first time, endorsed the notion of reparation based on gender with a transforming vocation. This ruling judged Mexico for the performance of its police and judicial system, in relation to the disappearance and homicide of those women in Ciudad Juárez. They included the relatives of these as victims in the proceedings against the State of Mexico for the harassment that they suffered from the authorities and other people due to their demand for justice in the disappearance and murder of the young women, including the theft of documents and equipment used in a civil organization created as a result of these events, "Integración de Madres por Juárez", for the investigation. These families were also subjected to defamation and harassment by local media. Such was the situation that the Monárrez family requested and obtained asylum in the United States of America.

What is relevant about this judgment in relation to the repair of the damage is to consider the text of the same as a form of reparation per se, insofar as international law recognizes that the declaratory judgment of the responsibility of a State is a way to repair the immaterial damages. In the same way, it is a form of moral reparation the fact that the mothers of the deceased were heard. To this we must add that Provision Two of the judgment imposes on the State the obligation to conduct the investigation again for these facts from a gender perspective, undertaking specific research lines regarding sexual violence as established in the Belém do Pará Convention, and the behaviour patterns of the area.

Another form of reparation that includes the innovative sentence that we are analyzing is the obligation imposed on the State to investigate the officials accused of irregularities in the investigation, and those who harassed the relatives of the three victims within a reasonable time. As a symbolic remedy, the State must publish the sentence in the Official Gazette of the Federation, in a newspaper of wide national circulation and in a newspaper of wide circulation in the state of Chihuahua; perform a public act of recognition of international responsibility in honour of the memory of the three murdered women, and erect a monument in memory of women victims of homicide due to gender discrimination in Ciudad Juarez. 
b) Proceedings regarding family matters: In cases of gender violence in which the victim and the aggressor are married, or have children in common, it is necessary to process the divorce, to decide on the custody of the children, establish an alimony, visitation rights, to decide issues related to parental authority over which the parents do not agree, challenge or recognize the filiation, etc...

It is advisable that all these issues are decided by the same judge who presided over the act of violence and therefore, is aware of the details of the case. Centralizing all the issues that may arise from the act of violence in a single judicial organ supposes, not only to expedite the process and reduce the number of files, but also to offer the victim a faster and more specialized response.

In the same way, agreement $n^{\circ} 244$ of the Supreme Court of Panama, of April 13, 2011 that adopts the letter of rights of the people before the justice in the judicial organ of the Republic of Panama ${ }^{13}$, also showed its sensitivity to the issue by recognizing in article 31 The right not to provide documentation that is in the power of the Public Administrations:

All persons have the right not to be required to provide documents that are in the possession of Public Administrations, unless the applicable laws provide precisely and expressly that such contribution must be verified by the person concerned.

The 100 Brasilia rules on access to justice for people in vulnerable conditions $^{14}$, states in its rule 38 :

The necessary measures will be adopted to avoid delays in the processing of the cases, guaranteeing the prompt judicial resolution, as well as a quick execution of the judgment. When the circumstances of the situation of vulnerability warrant it, priority will be given in the attention, resolution and execution of the case by the organs of the justice system.

c) non-payment of alimony: The maintenance payments that the civil courts establish for the support of the children, to be paid by the father, are frequently unpaid. In the event that the father is convicted of an act of domestic violence, the mother must go to a different judicial body, which is unaware of the circumstances of her case, to make the collection of such, 
effective. It is another tangential consequence of the act of violence, which could be mitigated by avoiding the long trip between the different judicial authorities, getting lost among the different jurisdictions of each one, as well as the technical-juridical language.

Imagine, for example, a sexual assault case in which the victim becomes pregnant. If the procedures are not simplified and the competences are not centralized in the same body, the victim has to report it and be immersed in a criminal process in which a painful and unpleasant subject will be discussed. However, the emotional suffering does not end there, because she must go to civil proceedings to be compensated for physical and psychological injuries. She should file a suit for a paternity test so that the identity of the father is determined in the Civil Registry. She will have to go back to the courts to have the right to receive a maintenance pension from the father to support that child, and if this alimony is unpaid, she must again file another suit for the forced collection of said amounts. Unifying all or most of the procedures in a single Court, will undoubtedly make the victim feel "less lost" during the proceedings. In addition, if a single procedure is focused on resolving several of these issues, efficiency is gained, the victim is given a response that conforms to international standards, and is not subjected to so-called secondary victimization.

Agreement No. 244 of the Supreme Court of Panama, of April 13, 2011 that adopts the bill of rights of persons before the justice system of the Republic of Panama, recognizes in Article 31 the right to an expeditious processing and to know the causes of the delays:

All persons have the right to the processing of matters that affect them to meet the requirements of agility and efficiency to obtain their resolution within the legal deadline or, if not, accurate information on the specific reason for the delay.

The UN, in its Strategies and Practical Measures of 2011, urges Member States to ensure that women who are victims of violence have access to prompt and fair compensation for the damage, including the right to demand reparation from the author of the facts or compensation from the State.

The specialization of judicial bodies was also a subject in the 100 Brasilia rules on access to justice for people in vulnerable conditions, which emphasize its importance on rule 40: 
Specialization. Measures will be adopted to specialize professionals, operators and servants of the judicial system for the care of people in vulnerable conditions. In the matters in which it is required, it is convenient to attribute the matters to specialized organs of the judicial system.

The idea of the "one stop center" 15 adopted in the United States, which offers centralized services to women victims of domestic violence is interesting. This avoids the dispersion of procedures, and above all the feeling of lack of protection generated by the system. This window houses several public agencies in the same building that provide assistance throughout the judicial process, help women to fill in the forms, explain what is the civil and criminal process derived from the crime, accompany them to the courts and help them to form plans for family security and find a home.

\section{JUDGING FROM A GENDER PERSPECTIVE}

The UN points out ${ }^{16}$ that the criminal justice system and legislators are not immune to accepted social values, cultural norms and practices. Consequently, the language and terminology used, or the total content of the judgment can reveal that sexist roles are incorporated with some normality in society in general, of which the judges are its reflection. Even the behaviour of the victim can be prosecuted, focusing on establishing a causal relationship between it and the commission of the crime.

The gender perspective is an instrument of analysis and action, of analysis insofar as it explains the phenomenon as a manifestation of historically unequal power relationships between men and women; in which violence is used to maintain relationships of dominance, and an instrument of action as necessary means to change the traditional concept of the role of women in society ${ }^{17}$.

Recognizing that the differences between men and women are of sociocultural nature gives us the possibility to modify them. The supposed naturalness of existing gender identities must be rejected and social change allowed over traditional gender identities that are supposed to be natural and immovable. Applying a gender perspective in the prosecution and judging therefore assumes two premises, the first, the existence of social differences and inequalities between men and women that are inadmissible, and the second, the socio-cultural recognition of these differences ${ }^{18}$. 
In the words of Inés Alberdi 19 "The gender perspective helps to understand the lives of women while not considering them as a necessary consequence of their nature."

The concern for the gender perspective reaches the European Court of Human Rights itself, which in the Valiuliene judgment against Lithuania (concurring opinion of Judge Pinto de Albuquerque) indicates that the useful effect of the Convention can only be achieved with an interpretation and application of its content with gender sensitivity, which implies taking into account the real inequalities between women and men, and the way in which this imbalance impacts their lives. Through this angle, it is evident that the mere act of domestic violence carries inherent humiliation and degrading treatment for the victim, which is exactly what the aggressor intends.

Within the case of Panama, there are expressions that reveal a certain social tolerance to the fact of gender violence. For example, it is very common to refer to the rupture of the hymen in sexual assaults, in which the woman had not had previous relationships, both at legal and medical level as "defloration" or "minor deflowered" 20 . This euphemism comes from centuries ago, where in a totally patriarchal society, women had a secondary and passive role, limited to serving the home and children. In this social context, the woman's greatest good was neither her intelligence nor her abilities, but her virginity, her "flower", which she had to preserve in order to give it to her husband on the wedding night.

Another quite frequent euphemism, which tries to hide the reality of the violence against women, is "marital conflicts" in the section "Proven Facts" of the judgments which refer to events in which a woman is beaten, insulted, threatened or harassed. The European Court of Human Rights in the case of Bevacqua and SC v. Bulgaria, in a judgment of June 12, 2008, ruled against this State for considering that the complaints presented by the woman against the husband, for being beaten continuously, were considered as a "private matter". The same High Court, in the case Opuz v. Turkey, judgment of June 9, 2009, ruled against this State for not having applied adequate protection measures to a wife, and the mother of the latter (finally murdered) versus the husband of the first, when the numerous complaints were filed as "a family affair". The two expressions that the European Court of Human Rights rejects, 
"private matter" and "family matter", are similar to that of "marital conflicts" which is used in the judgments of Panama.

Both expressions soften and downplay the fact that violence has played a part and it must be reported exactly as it happened. We should avoid using such expressions to camouflage serious acts such as rape or an act of physical or psychological violence. These are completely different realities that cannot be identified with the same words. Calling things by their names helps to make the phenomenon of gender violence visible and to raise awareness in society of its seriousness and extent.

The training of judges in this matter is fundamental, especially to learn to recognize the cycle of violence in which the victim may be immersed and understand their attitude that from the outside may seem illogical. This cycle of violence was explained by the psychologist Leonore Walker ${ }^{21}$ : Assaulted women are not constantly being attacked neither is their aggression totally randomly inflicted. One of the most surprising discoveries in the interviews was the defined cycle of aggression that these women experience. Understanding this cycle is very important if we want to learn how to stop or prevent incidents of aggression.

This cycle begins with a first phase of an accumulation of tension with anger over anything and aggressive reactions to any discomfort, a second burst of the tension that was accumulated in the previous phase and discharge in an acute incident to punish the behaviour of the woman that the husband considers inadequate, and the third of "honeymoon" or repentance, in which the tension diminishes, he apologizes, threatens to self-harm, tells her that if she leaves him it will destroy his life, etc. This cycle explains the continuity of the relationship from the point of view of the woman, even though when is a toxic and harmful one. It also helps us to understand why the battered woman constantly seeks the company of the abusive husband.

The cycle of violence causes the victims of the domestic Stockholm syndrome, disorientation, loss of memory, paralysis, loss of social skills, "magical" expectations of change in the aggressor ${ }^{22}$, loss of self-esteem and self-blame.

It is necessary to work on the training of judges to understand the victim and specifically the fact that all physical injuries always leave a psychological 
injury, which is difficult to overcome since the aggression comes from someone from whom one expects to receive respect, love and support. Another subject in which to work on is to create a climate of trust and security for the victim, understand their fear, even if it seems to be exaggerated, respect their right to confidentiality, and treat them equally without patronizing. This is necessary because the panorama that the victim of domestic violence faces is certainly devastating. Apart from the Syndrome of Battered Women that affect their credibility, we add the prejudices that society has on the subject, such as the way they dress, their role as a wife, or mother, not to give the image of battered women, to be a strong woman, not having previously reported any incident or the widespread mistrust for false allegations. These prejudices and this lack of credibility are extensively analyzed by the Views issued by the United Nations Committee on the Elimination of Discrimination against Women, on September 22, 2010 in the Karen Tayag Vertido case against the Philippines. In this case, Mrs. Vertido reported having been raped by a superior at work, and the sentence that acquitted the defendant did so based on the following arguments:

- "it is easy to make an accusation of rape; it is difficult to prove but more difficult for the person accused, though innocent, to disprove" (principles derived from the jurisprudence of the Philippine Supreme Court),

- the victim reacted with resistance to the aggressor in one moment and submission in another, which was considered not very credible,

- the victim did not attempt to escape despite the fact that the victim was not "a timid woman who could be easily cowed" (she was the Executive Director of the Chamber of Commerce and Industry of Davao, and he was President of that Chamber),

- the court considered it incredible that a man over sixty years old was able to reach ejaculation when the victim is resisting.

All these arguments were considered as gender stereotypes by the Committee, and considered that the judgment was based on myths, such as that educated women cannot be violated, or that a woman consents to a sexual relationship when she does not resist the physical force used by the aggressor. 
We need to work to destroy certain myths that justify violence, which must be eradicated, such as being in a drunken state, economic problems, stress at work, jealousy, lack of impulse control by the aggressor, etc.

We cannot forget the content of agreement No. 244 of the Supreme Court of Panama, of April 13, 2011 that adopts the letter of rights of people before the justice system in the Republic of Panama, unknown in sentences such as the one previously cited. This agreement recognizes in article 39 the right of victims to adequate treatment:

Victims of criminal offenses have the right to personal and institutional courtesy in personal appearance before the Judicial Body and to preserve their dignity, their right to honour and their image.

This right will enjoy special protection in cases of domestic or gender-based violence, in which the victims will be granted the protection they need, and will be understood in addition to the specific rights recognized by the approved norms or instruments in the development of gender policies and specific plans to combat this type of violence.

Agreement No. 626 of October 15, 2009, of the Plenary of the Supreme Court of Justice, which establishes as guidelines:

1. Raise awareness among the operators of the judicial system, users, assistants of the administration and civil society, on the importance of incorporating the perspective of gender, disability and human rights of the population discriminated against by the culture and social patterns of the patriarchal system in services and judicial processes. [...]

2. promote the incorporation of the gender perspective in judicial resolutions in all instances of the judicial structure eradicating sexist language, based on the human rights of women, persons with disabilities, young people in conflict with the law, and carrying out the tactical and legal assessment from the vision of diversity.

\section{THE IMPORTANCE OF PREVENTION}

The report by the United Nations Special Rapporteur Rashida Manjoo in 2011 indicates that the efforts of States to comply with the "due diligence" standard $^{23}$ should not focus solely on legislative reform, access to justice and the provision of services to victims; they must also address prevention 
issues, especially in order to attack the structural causes that give rise to violence against women.

The psychiatrist Robert Jesse Stoller found out in his studies that what determines masculine and feminine identity and behaviour is not biological sex, but the fact of having lived from birth the experiences and customs traditionally attributed to men and women. The author concludes that the acquisition of an identity is more important than the genetic, hormonal and biological load. Many of the issues that we unconsciously think are natural attributes of men and women, are actually socially constructed characteristics that are not related to biology, based on the difference in treatment that children receive. Therefore the educational work, and control of the messages transmitted through advertising, music, film, television, powerful sources of information, can have very beneficial effects in changing the social conception of women, and consequently, in the acts of violence committed against them.

After several studies by anthropologists, biologists and psychologists trying to determine what is innate and what is acquired in the masculine and feminine characteristics of people, it has been proved that the female status varies from one culture to another, and even from a religion to another, but always with the constant characteristic of the subordination of women, to men.

It is necessary to profoundly raise the social awareness, and provide training for legal operators in said fact. As an example we can mention the social psychology experiment that was conducted by Dr. Walter Mischel of the University of Stanford, California. This project consisted of random groups of people, from all social, cultural, religious and economic strata, spending some time observing newborn babies in a Hospital, and recording their observations for more than six months. The staff of that Hospital had been ordered that when the observer group arrived, they had to give the babies a cover and a sheet, pink to the boys and blue to the girls. The study revealed that the observers were influenced by the colour of the sheets describing as "a very sweet girl" a male, or "a very energetic little boy" to a girl. The gender of the babies was what conditioned the response, not the sex of the same.

The awareness that domestic violence is a widespread phenomenon and affects women from all social strata must also be addressed, according to the United Nations Special Rapporteur Rashida Manjoo in its 2011 report. 
Preconceived ideas that it only affects low social strata or depressed economies should be rejected.

The prevention of violence against women also involves the protection of girls. Resolution 65/145 of December 18, 2009, of the General Assembly of the United Nations on "The girl ", indicates that they are more exposed to discrimination and violence, and the Assembly is "deeply concerned" by the consequences of unprotected and premature sexual relations, social violence, rape or incest; as well as premature procreation and limited access to sexual health services. According to the UN, this premature motherhood, starting at age 11, is an impediment to improving the educational and social situation of girls, and therefore another factor for them to become victims of gender violence.

\section{MEDIATION IN GENDER VIOLENCE}

As it is well known, mediation as a means of resolving conflicts is totally prohibited for the subject of gender violence by recognized studies, such as the UN Division for the Advancement of Women of 2010, Directive 2012/29/ EU of the European Parliament and, in the Spanish case, Article 44 of the Organic Law on Comprehensive Protection Measures against Gender Violence $1 / 2004$. This prohibition is even integrated into the law of Panama, through Agreement No. 626 of October 15, 2009, of the Plenary of the Supreme Court of Justice, which establishes in Article 1:

The institutional policy of access to justice is based on the following principles: [...]

\section{Equality in the Conciliation and Mediation.}

Determine the balance between the parties, which implies equality in the power relations since an imbalance of power could vitiate the will of the disadvantaged party. This principle must be guaranteed in any of the alternative dispute resolution processes for its validity.

Specifically, the guidelines of said agreement say:

9. Prohibit the alternative resolution of conflicts in cases of gender violence and in cases involving women, adolescents in conflict with the law and persons with disabilities, apply them only when equality between the parties is guaranteed. 
Mediation is a procedure in which the parties to the conflict voluntarily try to reach an agreement on their own with the help of a mediation professional, who does not have decision-making functions, but manages the procedure. The agreement is a mandatory private contract between the parties.

The prohibition of mediation in this matter has its cause in the relationship of asymmetry of power between both parties involved. The victim is psychologically subjected to the aggressor, has feelings of guilt for the situation that the family goes through and can accept agreements that do not benefit her or even put her in danger. On the other hand, acts of violence are not sanctioned criminally, the aggressor is given an appearance of impunity and the aims of general prevention ${ }^{24}$ that is associated with every penalty, disappear.

The UN recommends that legislation explicitly prohibits mediation in all cases of violence against women ${ }^{25}$, both before and during legal proceedings. The aforementioned study indicates that mediation on violence against women is offered in several countries as an alternative to criminal proceedings and family processes, and indicates that the main problem of withdrawing these matters from judicial control presupposes that both parties have the same bargaining power, that both parties are equally guilty of violence and reduces the responsibility of the perpetrator.

The Panamanian national legislation itself, in its Law $82 / 13^{26}$, article 15.4 , establishes that the State has the obligation to implement in all areas the international recommendations on women's human rights, and promote the removal of socio-cultural patterns that entail and sustain gender inequality and relationships of power over women. However, article 1961 of the Judicial Code estates:

In cases where the conditional suspension of the sentence is possible ${ }^{27}$, the Prosecutor or the accused may request, until the resolution that sets the date of the hearing, the conditional suspension of the criminal process. If the accused is in agreement with the suspension and admits the facts that are imputed to him, the judge can order the conditional suspension of the process, provided that the accused has repaired the damages caused by the crime, sufficiently consolidate the reparation, even through agreements with the offended, and formally assume the obligation to repair the damage to the extent of its possibilities. 
The suspension of criminal proceedings does not impede the exercise of civil action in the respective courts.

The possibility of provisionally concluding the process through the aforementioned article is not excluded for cases of violence against women. Through this figure, the defendant recognizes the facts, and undergoes a measure of curative security instead of imposing a penalty, in exchange for committing himself not to re-attack or humiliate the victim, which is present in said agreement and gives her consent and acknowledges that the damage has been repaired. A mediator as such does not formally intervene, but it could well be the prosecutor together with the lawyers of both parties, who, by asserting this function, help the parties to that "cordial entente" or "non-aggression pact" in order to paralyze the procedure, perhaps indefinitely.

If the only condition to which the provisional suspension is subject ${ }^{28}$ is to prevent the recurrence of acts of domestic violence, it is highly likely that, even repeating these, the victim does not inform the authorities with the ultimate aim of not harming her partner whom she emotionally depends on and not break up the family, which society would blame her for.

Finally, in addition to what has already been said about the conditional conclusion of the procedure and its assimilation to mediation, we must bear in mind that this procedural figure in itself violates the Resolution of the United Nations General Assembly 65/228 of Strengthening responses on crime prevention and criminal justice to violence against women, since that resolution literally "urges Member States to end impunity for violence against women by investigating, prosecuting with due procedural guarantees and punishing all perpetrators", and what mediation achieves is precisely the opposite, to paralyze the investigation and avoid prosecution.

\section{References}

"Diagnosis on the application of the criminal normative framework regarding the elimination of violence against women in judicial resolutions” (2011) Panamá

"Gender dimensions of agricultural and rural employment: Differentiated pathways out of poverty", (2010) published by The United Nations Food and Agriculture Organization, the International Fund for Agricultural Development and the International Labour Office. Rome. 
Agreement No. 244 of the Supreme Court of Panama of April 13, 2011 that adopts the letter of rights of the people before justice in the judicial organ of the Republic of Panama

Agreement No. 626 of October 15, 2009, of the Plenary of the Supreme Court of Justice of Panama, approving the institutional policy of access to justice and gender of the judicial organ

ALBERDI, I. (1999)The meaning of gender in the Social Sciences.

Case Karen Tayag Vertido against the Philippines of the Committee for the Elimination of Discrimination against Women of the United Nations, September 22, 2010

Case of the Inter-American Court of Human Rights González, Herrera and Benerice (cotton field) against Mexico, of November 16, 2009

Directive 2012/29 / EU of the European Parliament

Inter-American Convention to Prevent, Punish and Eradicate Violence against Women Belém do Pará

Judicial Code of Panama

Law 82/13 of the Republic of Panama

Manual for Legislation on Violence against Women, United Nations, New York, (2010)

MONTALBÁN HUERTAS, I. (2006) The Comprehensive Law against Gender Violence $1 / 2004$ as a normative instrument. Balance of one year in the judicial field. Notebooks on Judicial Law IV / 2006

Organic Law on Comprehensive Protection Measures against Gender Violence $1 / 2004$

PAZ RODRÍGUEZ, J (2011) The mechanisms of violence, their consequences for victims and their implications for professional intervention.Digital Training Notebooks of the CGPJ 7/2011

POLO GARCÍA, S. (2012) Basic concepts: domestic violence. Gender violence and gender perspective. Specific characteristics of gender violence. Digital training notebooks 9/2012.

Report of the UN Special Rapporteur on violence against women, its causes and consequences, (2011)

Resolution 65/145 of December 18, (2009), of the General Assembly of the United Nations on "The girl" 
Resolution of the General Assembly of the United Nations 65/228 of Strengthening the responses on crime prevention and criminal justice to violence against women, of December 21, (2010)

Strategies and practical measures. Updated model for the elimination of violence against women in the field of crime prevention and criminal justice. 2011 Resolution approved by the UN General Assembly of December 18, 2013

The 100 Brasilia rules on access to justice for people in vulnerable conditions.

WALKER, L. (1979) The battered woman syndrome. New York: Sheri W. Sussman. ISBN 9780826170989

\section{Endnotes:}

${ }^{1}$ ECHR Judgment Valiuviene v. Lithuania, concurring opinion of Judge Pinto de Albuquerque

${ }^{2}$ POLO GARCÍA, SUSANA. Basic concepts: domestic violence. Gender violence and gender perspective. Specific characteristics of gender violence. Digital Training Notebooks 9/2012.

3 Strategies and practical measures. Updated model for the elimination of violence against women in the field of crime prevention and criminal justice. 2011

${ }^{4}$ In its comprehensive report "Gender dimensions of agricultural and rural employment: Differentiated pathways out of poverty", published by the Food and Agriculture Organization of the United Nations, the International Fund for Agricultural Development and the International Work, in Rome, 2010.

${ }^{5}$ After visiting Kyrgyzstan, Zambia, Algeria, El Salvador and the United States of America

${ }^{6}$ https://www.unodc.org/mexicoandcentralamerica/es/webstories/2011/taller-devalidacion.html

7 In case the victim wants to be civilly compensated for the damages inflicted through the act of violence

${ }^{8}$ In addition to the inefficiency that in purely material terms supposes for the Public Administration two different procedures, when it could have been decided in only one.

${ }^{9}$ http://www.organojudicial.gob.pa/wp-content/uploads/2009/11/626completo.pdf

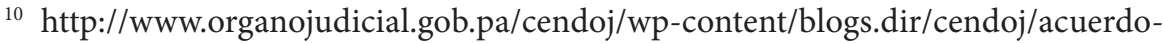
244-de-13-de-abril-de-2011.pdf 
${ }^{11}$ XIV Ibero-American Judicial Summit, held from March 4 to 6, 2008. Full text: http://www.derechoshumanos.net/normativa/normas/america/ReglasdeBrasilia2008.pdf. The 100 Brasilia rules have been incorporated into Panamanian law in Agreement No. 245 of the Plenary of the Supreme Court of Justice of the Republic of Panama.

${ }^{12}$ http://www.libertadciudadana.org/archivos/Biblioteca\%20Virtual/Leyes\%20Nacionales\%20Indigenas/Juridico/Codigos/Codigo\%20Judicial\%20de\%20la\%20Republica\%20de\%20Panama\%202010.pdf

$13 \mathrm{http}: / /$ www.organojudicial.gob.pa/cendoj/wp-content/blogs.dir/cendoj/acuerdo244-de-13-de-abril-de-2011.pdf

${ }^{14}$ XIV Ibero-American Judicial Summit, held from March 4 to 6, 2008. Full text: http://www.derechoshumanos.net/normativa/normas/america/ReglasdeBrasilia2008.pdf

The 100 Brasilia rules have been incorporated into Panamanian law in Agreement No. 245 of the Plenary of the Supreme Court of Justice of the Republic of Panama.

${ }^{15}$ Hennepin County Domestic Abuse Service Center of Minnesota

${ }^{16}$ Strategies and practical measures. Updated model for the elimination of violence against women in the field of crime prevention and criminal justice. 2011

17 MONTALBÁN HUERTAS, INMACULADA. The Comprehensive Law against Gender Violence 1/2004 as a normative instrument. Balance of one year in the judicial field. Notebooks on Judicial Law IV/2006

${ }^{18}$ POLO GARCÍA, SUSANA. Basic concepts: domestic violence. Gender violence and gender perspective. Specific characteristics of gender violence. Digital Training Notebooks 9/2012

19 ALBERDI, INÉS. The meaning of gender in the Social Sciences.

${ }^{20}$ For example, in the cassation appeal of the Judgment of March 8, 2012 issued by the Second Superior Court of the First Judicial District, resolved by the Supreme Court of Justice on September 4, 2014. The text of that sentence and of many others that use the term, can be consulted in the search engine of the judicial organ of Panama: http://bd.organojudicial.gob.pa/registro.html

${ }^{21}$ The battered woman syndrome, 1979

22 PAZ RODRÍGUEZ, JUAN IGNACIO. The mechanisms of violence, their consequences for victims and their implications for professional intervention. Digital Training Notebooks of the CGPJ 7/2011

22 The "due diligence" of the States includes the obligation to: 
a) prevent acts of violence against women

b) investigate and punish all acts of violence against women

c) protect women from any act of violence

d) provide reparation and reparation to victims of violence against women

${ }^{24}$ The general prevention of punishment seeks to dissuade individuals from executing legally prohibited behaviour, and projects in society the expectations of compliance with the norms.

${ }^{25}$ Manual for Legislation on Violence against Women, New York, 2010

${ }^{26}$ https://oig.cepal.org/sites/default/files/2013_pan_ley82.pdf

${ }^{27}$ Custodial sentences not exceeding three years, weekend arrest, house arrest or fine-day imprisonment. Article 98 of the Criminal Code.

${ }^{28}$ Article 1962 of the Judicial Code allows other conditions to be imposed 